\title{
Additive Manufacturing: The Most Promising Technology to Alter the Supply Chain and Logistics
}

\author{
Mohsen Attaran \\ School of Business and Public Administration, California State University, Bakersfield, California \\ Email: mattaran@csubak.edu
}

How to cite this paper: Attaran, M. (2017) Additive Manufacturing: The Most Promising Technology to Alter the Supply Chain and Logistics. Journal of Service Science and Management, 10, 189-205. https://doi.org/10.4236/jssm.2017.103017

Received: January 18, 2017

Accepted: April 27, 2017

Published: April 30, 2017

Copyright $\odot 2017$ by author and Scientific Research Publishing Inc. This work is licensed under the Creative Commons Attribution International License (CC BY 4.0).

http://creativecommons.org/licenses/by/4.0/ (c) (i) Open Access

\begin{abstract}
To compete in a global economy, manufacturers are forced to move towards low volume production of innovative and customized products with high added value. Three-dimensional printing, also known as additive manufacturing ( $\mathrm{AM}$ ) or rapid prototyping enables and facilitates production of moderate to mass quantities of products that can be individually customized. The technology is truly innovative with endless product design possibilities and potential to enhance global supply chain capabilities. The technology improves efficiencies of the entire supply chain, from the cost of distribution to assembly and carry, all the way to the component itself. This article reviews evolution of new supply chain models, examines some of the potential benefits of AM in challenging traditional manufacturing constraints, explores its impact on the traditional and global supply chain and logistics, and investigates its transformative potential and its impact on various industry segments.
\end{abstract}

\section{Keywords}

3D Printing, Additive Manufacturing, Rapid Prototyping, 3D Implementation, Decentralized Manufacturing, Manufacturing Lead Time

\section{Introduction}

3D printing uses a computer aided (CAD) design to translate the design into a three-dimensional object. The design is then sliced into several two-dimensional plans, which instruct the 3D printer where to deposit the layers of material. The terms $3 \mathrm{D}$ printing and additive manufacturing have become interchangeable. The terminology additive manufacturing or AM refers to the technology, or additive process, of depositing successive thin layers of material upon each other, 
producing a final three dimensional product. Each layer is approximately 0.001 to 0.1 inches in thickness [1]. A wide variety of materials can be utilized; namely, plastics, resins, rubbers, ceramics, glass, concretes, and metals [2].

In the past few years, AM technologies have moved way beyond prototyping applications to play a more critical role in improving production approaches and enhancing supply chain capabilities. The technology has the potential to enable manufacturers to alter their production processes and reduce the number of steps that a product must undergo.

The technology has improved processes in many industries, including aerospace, automotive, industrial products, consumer products, defense, architecture, and healthcare. Experts believe that this technology will keep growing at a fast pace and play a major role in the future of supply chains.

There has not been very much academic research about 3D printing and its effect on the global supply chains [3] [4] [5] [6]. This research area is largely underdeveloped compared to other domains. Therefore, there is a strong need to address the research that is specifically concerned with the impacts of 3D printing on supply chains and supply chain management. The objective of this article is to explore basic issues related to $3 \mathrm{D}$ printing technology, including its promises, as well as its pitfalls. Another objective is to investigate renewed trends in 3D printing technology and its promises for altering manufacturing and supply chain. This section evaluates evolving technologies and trends and discusses the obstacles to full-scale 3D printing rollouts. Section II highlights the potential of this technology in challenging traditional manufacturing constraints. Section III discusses different ways where this technology could alter and improve traditional and global supply chain and logistics. Section IV reviews evolution of new supply chain models. Section V highlights potential impacts on industries supply chain. Finally, section VI summarizes the paper.

\section{a) A Three-Phase Evolution of Technology}

Charles W. Hull of 3D Systems Corp. created the first working 3D printer in 1984. He named the machine Sterolithgraphy Apparatus [2]. The technology was very expensive and not feasible for the general market in the early days. As we moved into the $21^{\text {st }}$ century, however, costs drastically decreased, allowing $3 \mathrm{D}$ printers to find their way into many industries.

All 3D printers use additive processes, differing mainly in the way layers are built to create the final object. Melting or softening material is used to produce the layers (Figure 1). The most common technologies using this way of $3 \mathrm{D}$ printing are Selective Laser Sintering (SLS) and Fused Deposition Modeling (FDM). SLS utilizes a high powered laser to fuse small particles of plastic, metal, ceramic or glass powders into a mass that has the desired 3 dimensional shape.

FDM utilizes thermoplastic materials injected through indexing nozzles onto a platform. Finally, Stereolithography (SLA) utilizes laser technology to cure layer upon layer of photopolymer resin [7].

$3 \mathrm{D}$ printing has undergone a three phase evolution process from prototyping and mockups of new designs by product designers to final consumers owning a 
Types of 3D-Printing

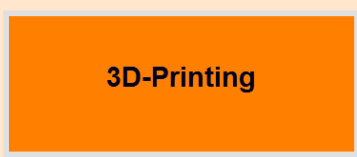

FDM
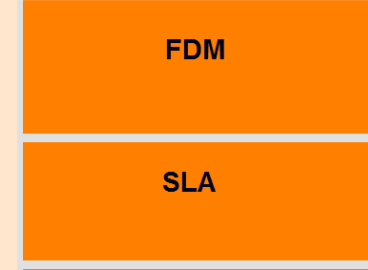

SLS
Material

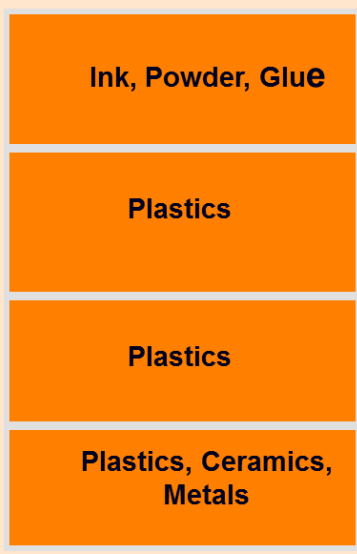

Process

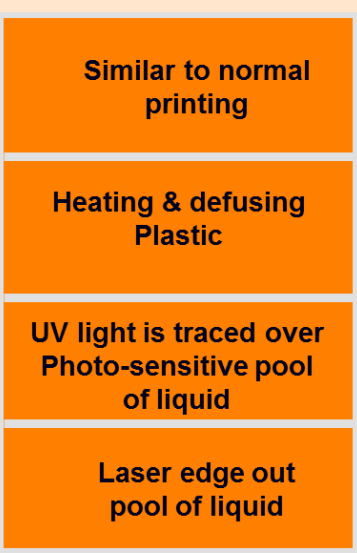

Figure 1. Types of AM technologies.

Table 1. The evolutionary phases of 3D printing.

\begin{tabular}{|c|c|}
\hline Evolutionary Phases of 3D Printing & Applications \\
\hline $\begin{array}{l}\text { Phase I: Rapid Prototyping } \\
\text { (PAST) }\end{array}$ & $\begin{array}{l}\text { - Product designers and architects used technology to make } \\
\text { mockups and prototypes of new designs } \\
\text { - Small batch manufacturing of high value/complex products }\end{array}$ \\
\hline $\begin{array}{l}\text { Phase II: Machine Tool Manufacturing or } \\
\text { Direct Digital Manufacturing } \\
\text { (NOW) }\end{array}$ & $\begin{array}{l}\text { - Technology is used to create finished goods } \\
\text { - Service parts with high volume/high value forms } \\
\text { - High volume products with short lifespan }\end{array}$ \\
\hline $\begin{array}{l}\text { Phase III: Decentralized Manufacturing } \\
\text { (FUTURE) }\end{array}$ & $\begin{array}{l}\text { - Fast moving and mass produced consumer goods: consumers } \\
\text { own 3D-printer, print their own parts and can become } \\
\text { micro-manufacturer }\end{array}$ \\
\hline
\end{tabular}

3D printer and own "factories in their homes" (See Table 1) [8] [9].

According to a 2014 report by Wohlers, the worldwide revenues from 3D printing are expected to double to $\$ 5$ billion by 2016 , and exceed $\$ 21$ billion by 2020. Drivers for the rapid growth are the reduction in cost to access the technology as well as an increase in applications [10].

\section{b) Limitations of 3D Printing}

AM has existed for over thirty years, but only recently has this technology risen in popularity and captured the interest of both technology experts and the public. The last major AM patent for Fused Deposition Modeling or FDM, expired in 2009 where these printers could be produced without infringing on intellectual property, creating a newfound interest and investment in $3 \mathrm{D}$ printing [11]. Since the industry only began to grow substantially after 2009 , the industry is still very young, and technological advancements in $3 \mathrm{D}$ printing, as well as the discovery of new applications of the technology, are still in development. It may be a number of years before $3 \mathrm{D}$ printing truly revolutionizes manufacturing and other industries in a considerable way. 
While AM is a breakout technology poised to change manufacturing and a variety of other industries, implementation of the technology is only in its infancy and there are numerous challenges in applying AM in a way that would allow for its significant and rapid growth. The major obstacles to implementation are summarized below and range from the size of objects manufactured, to government, liability, and intellectual property issues [12] [13]:

- Limited choices for materials, colors, and surfaces

- Higher cost for large production runs

- Limited strength and resistance to heat \& motions \& color stability

- Limited product dimensions

- Lower precision relative to other technologies

- Unchecked production of dangerous items

- Liability and intellectual property issues

\section{Impact on Manufacturing}

The changing demands of major industries like the automotive and aerospace that utilize AM will shape the direction and the type of technological innovations that will be required to keep up with the demands of the market. AM is truly innovative; it opens up new opportunities and provides many possibilities for companies looking to improve manufacturing efficiency.

AM significantly streamlines traditional methods and has the potential to become the norm over decades to come. The technology provides freedom of design using standard CAD software, and it is not limited to manufacturing technology. It also enables cost effective product customization [14] (Figure 2).

There are two main categories of applications of AM in manufacturing indus-

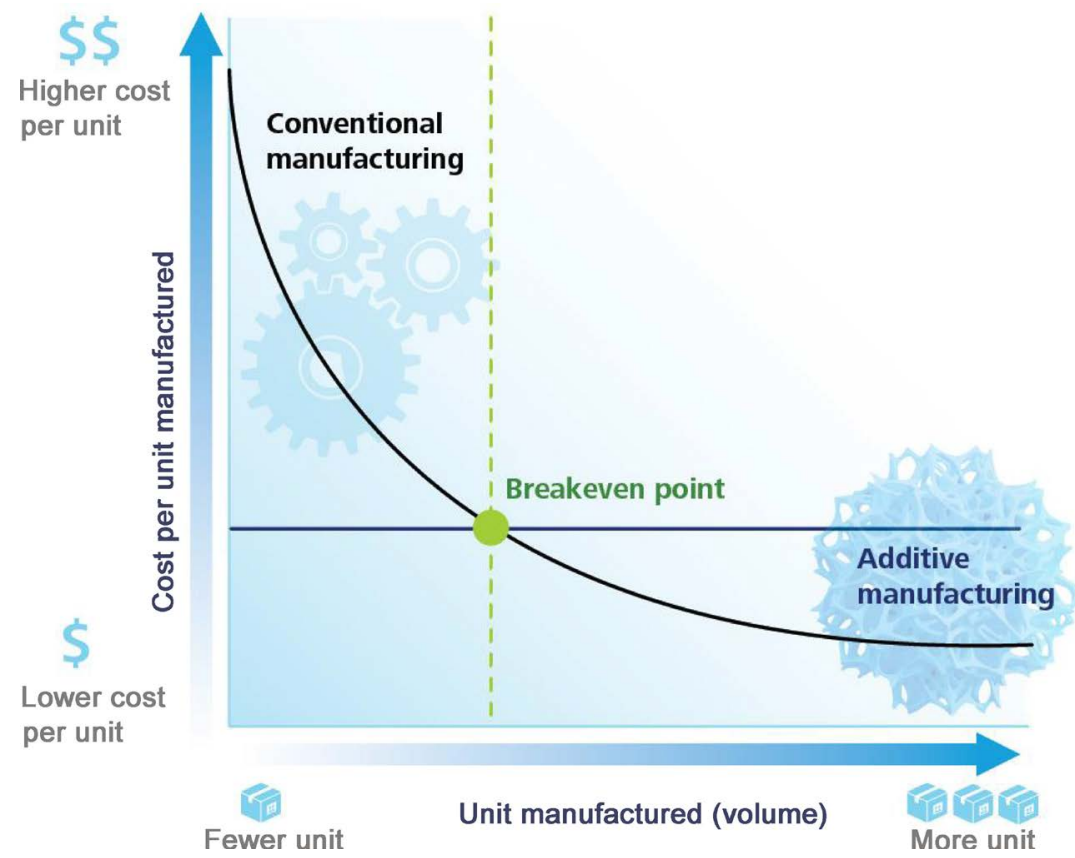

Source: Janssen 2014

Figure 2. Cost comparison: convectional vs additive manufacturing. 
try, as discussed below [2]:

a) Rapid Prototyping: Rapid Prototyping provides reductions in cost and time. The costs and time saving comes from the prototype manufacturing and product testing stages of innovation. When producing one kind of product, it is very costly to use traditional manufacturing. Additionally, when AM is utilized to produce a prototype, it is much faster compared to traditional manufacturing. Cost and time savings provides more focus on other areas of innovation, making companies more efficient and competitive at innovation.

b) Component Manufacturing: The production of component parts is the other main application of AM technology. Industries that require low quantities of parts that must be printed to certain specifications with little tolerance for error most utilized $3 \mathrm{D}$ printing. Over $20 \%$ of the $3 \mathrm{D}$ printing market is made up of component part production for the aerospace and automotive industries [15]. In 2013, the aerospace industry had in excess of 22,000 parts in use [16]. The level of success and growth of $3 \mathrm{D}$ printing in these sectors is an indicator that the level of quality arising from $3 \mathrm{D}$ printing parts is satisfactory to tough industry standards.

AM won't replace existing conventional subtractive production methods. However, it is expected to revolutionize many niche areas. Exponential growth is expected to be on the horizon. Savings in cost and speed have been predicted in the literature [15]-[22].

According to Ed Morris, director of NAMII, “Additive manufacturing will democratize the manufacturing process". Table 2 provides a summary of 3D printing greatest potential and its capability to challenge many traditional (subtractive) manufacturing constraints.

\section{Altering Supply Chain and Logistics}

Supply chain accounts for a company's largest expenses. A recent survey finds out that the supply chain expense is more than 5 percent of the total value of goods. The savings in overall management of supply chain including transportation, and inventory carrying costs could be substantial. To be competitive, today's global supply chain organizations must find cost reduction initiatives. The desire to cut supply chain costs made RFID technology one of the most discussed retail technologies in 2000 [23] [24]. It seems the decade of 2010 belongs to $3 \mathrm{D}$ printing.

Center for Additive Manufacturing and Logistics defines the AM supply chain as an interconnected set of independent supply networks of goods and services, catering to the demands of end consumers of products generated using AM technology. This supply chain includes various members like machine vendors, material manufacturers, software providers, logistics operators, and research centers. 3D printing open up new opportunities and is slowly emerging as a valuable way to improve supply chain efficiencies.

a) Impact on the Traditional Supply Chain

The main objective of this study is to investigate the impacts of $3 \mathrm{D}$ printing on 
Table 2. AM impact on manufacturing.

\begin{tabular}{cll}
\hline Manufacturing Improvements & \multicolumn{1}{c}{ Key Enabling Capabilities } \\
\hline Industrial Efficiency & - & \multicolumn{1}{c}{ Reduce material inputs for leaner manufacturing } \\
& & - \\
Mastems or subsystems
\end{tabular}

global supply chain and logistics. According to several academic studies, AM has potential to reduce complexity in supply chain in several ways [14] [25] [26] [27] [28]. These researchers believe that an important benefit of the technology lies in the consolidation of components into a single product, which consequently leads to a reduction in inventory complexity. The removal of assembly and pre-assembly steps, and the potential to reduce the supplier base of the company have also been mentioned as other AM benefits. They generally agree that the impacts of AM could have great outcomes for the logistics and inventory sector [19]. Table 3 highlights the advantages of AM impacted supply chain over traditional supply chain.

AM significantly streamlines traditional methods and has the potential to become the norm over the decade to come. AM is a strong enabler of product customization and can have remarkable impacts on production and distribution. By involving clients in the design and production, stages and tailoring individualized offers to each customer, AM has the potential to reduce costs and increase profits. As a result, supply chain can quickly react to changes in the marketplace. 
Table 3. Improving the traditional supply chain.

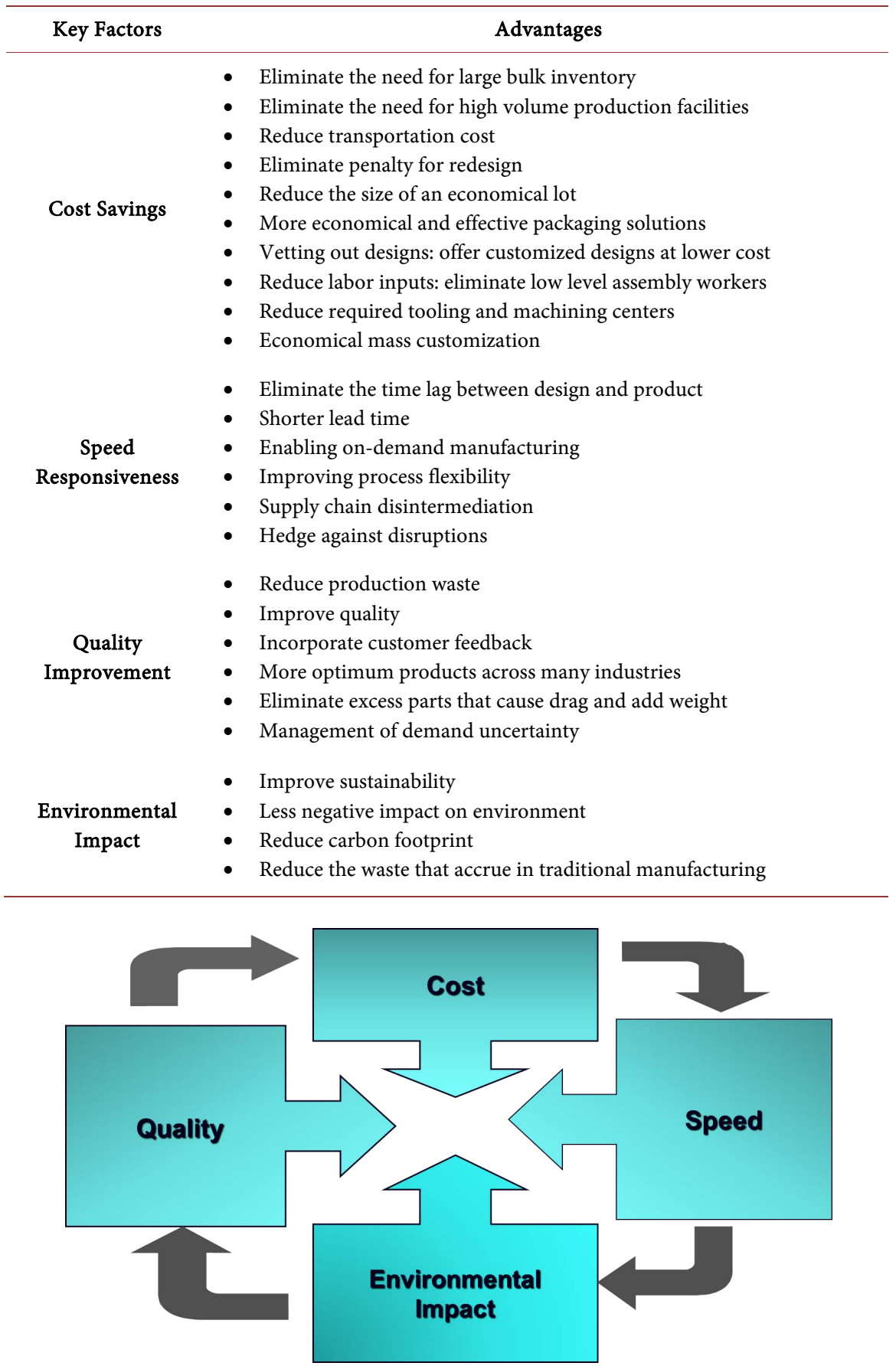

Figure 3. Improving global supply chain.

In summary, AM technologies can affect supply chains in many ways, including accelerated product development, reduced economical lot size, increased production flexibility, and reduced material waste. Adopters can rip the benefits from sourcing of materials to logistics and product distribution.

This study used research literature and concluded that companies are using AM to alter their supply chains to improve performance in the following four key areas of cost, speed, quality, and environmental impact (Figure 3). Table 3 
also summarizes AM technologies impact on the supply chain.

\section{b) Impact on the Global Supply Chain}

The impact of AM technologies on the global setup of supply chains can be very disruptive, as studied in a few recent publications. The technology has the potential to eliminate the need for both high volume production facilities and low-level assembly workers, thereby drastically reducing supply chain cost. Manufacturing can take place almost anywhere at the same cost. Thereby, it is no longer financially efficient to transport products moving across the globe to get to the customer. With the potential to support re-shoring and local sourcing, the technology has the potential to tear established global supply chain structures apart and re-assembles it as a new, local system [26] [29]. Furthermore, the technology creates a close relationship between design, manufacturing and marketing. By manufacturing items closer to their end destination, there is the potential to reduce logistics costs and environmental impacts. As a result, the use of this technology holds the potential to move some manufacturing away from low-wage countries and closer to the consumers. The technology could transform the global supply chain to a globally connected, but totally local supply chain.

\section{c) Impact on Global Logistics}

According to a recent study, "software-defined supply chain" has the potential to dramatically reduce lead times, costs, and overhauls the logistics industry. A new sector of the logistics industry would emerge dealing with the storage and movement of raw materials such as plastics, powder, glue, ceramics, etc. which 'feed' the 3D Printers. With increased popularity of 3D printers, the home delivery market of these materials would increase. Furthermore, freight miles are a key feature of contemporary transportation. 3D printing has the potential to reduce the number of freight miles needed for transportation drastically. There are other major impacts on the global logistics industry as summarized below [30]:

- Mass customization results in reduction of inventory levels and warehouse requirements.

- Goods produced in other countries could be manufactured locally leading to reduction in shipping.

- Manufacturing processes are increasingly handled within a single facility therefore, logistic suppliers will be less involved in upstream supply chains.

- There will be a shift from "push supply chains" to "pull supply chains". The long production runs for mass production (economies of scale) will give way to limited production runs mass customization and build-to-order products (economy of scope).

- Manufacturer will be better able to react to customer demands quickly.

- There will be less work-in-progress and finished goods in stock and in transport reducing the overall supply chain system costs.

- One of the first sectors to be affected by AM technology is the service parts logistics sector. AM can custom design service parts within a very short time frame and eliminate huge amount of redundancy that is built into supply 
Table 4. Key changes: traditional supply chain vs AM alternative.

\begin{tabular}{ll}
\hline \multicolumn{1}{c}{ Traditional Supply Chain } & \multicolumn{1}{c}{ AM Impacted Supply Chain } \\
\hline Push supply chain & Pull supply chain \\
Long lead times & Shorter manufacturing lead time \\
High transport costs & Reduced transportation cost \\
Complex distribution networks & Reduced inventory \\
Dependency on economies of scale & Dependency on economies of scope \\
Lengthy response to customer demand & $\begin{array}{l}\text { Quick response to customer } \\
\text { demand }\end{array}$ \\
Challenging management of demand uncertainty & $\begin{array}{l}\text { Easier management of demand } \\
\text { uncertainty }\end{array}$ \\
High level of required inventory & Reduction in required inventory \\
Manufacturing far away from point of use & Manufacturing closer to point of use \\
Using intermediaries in the global supply chains & Supply chain disintermediation \\
Supply chain disruptions-broken machines, regional & Hedge against disruptions \\
turmoil, or shipping delays &
\end{tabular}

chains to enable parts to be dispatched in a very short timescale. This would make global and national parts warehouse unnecessary to fulfilling customer needs.

\section{d) Benefits Gained}

Table 4 provides an overview of key changes in traditional supply chain versus AM alternatives. A list of efficiencies and benefits companies could possibly gain by using AM to improve supply chain performance is described on this section. Those efficiencies run the entire supply chain, from reducing scrap, reducing inventories, lowering complexity, maximizing customization, and improving assembly cycle times.

1) Shorter Manufacturing Lead Time: $3 \mathrm{D}$ printing of parts available to the consumer could be an additional aspect of the industry revolutionized by $3 \mathrm{D}$ printing technology. 3D printing would make it possible for consumers to print their own parts for fixing their personal items. Consumers can become micro-manufacturers, resulting in decentralized manufacturing.

2) Reduced Inventory: $3 \mathrm{D}$ printing facilitates on-demand manufacturing of replacement parts. The technology makes it possible to have parts printed in remote locations by local distributors and service providers, the delivery of goods is no longer a restriction. This results in shortening of the supply chain and saving since shipping and stockpiling inventory is not necessary. The need for large bulk inventories will be a thing of the past.

3) Reduced Lot Sizes: The technology enables smaller manufacturing runs potentially reducing manufacturing lot sizes. This could allow companies to reduce inventory holdings.

4) Shorter Time-to-Market: 3D printing could also potentially accelerate prototyping by reducing time-to-market. Inventors could quickly make low-cost iterations that incorporate customer feedback. Designers are able to make li- 
mited quantities and multiple varieties of an item for market testing cheaply.

5) Reduced Transportation Cost: $3 \mathrm{D}$ printing can reduce transportation cost of global logistics network by enabling companies to station local manufacturing centers closer to markets. This could result in reducing the length of the supply chain.

6) Reduced Production Waste: Traditional manufacturing cut away material and create large amount of waste. AM technology builds in layers and has no production waste. Moreover, additive manufacturing would help companies improve the productivity of materials by eliminating the waste that accrues in traditional (subtractive) manufacturing and would thus spur the formation of a beneficial circular economy.

7) More Efficient Packaging: 3D printing is now using materials including high-performance thermoplastics such as polycarbonate and ABS. Using these materials, 3D printing, can achieve designs that fluctuate in thickness and patterns with varying sizes and unique shapes. Packaging industries are finding 3D-printed thermoforming patterns an increasingly more economical and effective solution to challenging product designs [31].

8) Improved Product Range via Customization: Many companies offer a long list of low-volume and potentially slower moving items, like customization and spare part providers. Products like these are costly to handle and keep track of. 3D printing could enable manufacturing on-demand, enabling businesses to support a wider range of products, at a competitive cost level, without the need to hold extra inventory [32].

9) Hedge against Disruptions: AM can provide a low cost and reliable back up plan when disruptions occur. AM enables mid-market manufacturers to temporarily produce some components in-house. That would help when vendors have short-term supply problems such as broken machines or shipping delays.

10) Improved Sustainability: Traditional global sourcing generates high emissions resulting from high volume physical movements' of materials and goods. Products made by 3D printers have a smaller environmental footprint due to sustainable local production and the reduced physical movement of materials and goods. According to a recent study, 3D printing is capable of reducing the impact of industrial and manufacturing activities on the environment [33].

\section{Evolution of New Supply Chain Models}

As AM becomes more available, it will play a more critical role in future supply chains. It is estimated that AM will be implemented more widely in less than 10 years. AM enables many new supply chain models as summarized in Table 5 [30]. These new models will have a potential tangible impact on the cost and capability of supply chains such as drastically reduced delivery times and increased on time, in-full product delivery. These models will streamline supply chain networks with reduced warehousing requirements and a reduction in inventory levels. 
Table 5. Formation of new supply chain models.

\begin{tabular}{|c|c|c|}
\hline Models & Process & Benefits Gained \\
\hline $\begin{array}{l}\text { Streamlined } \\
\text { Logistics }\end{array}$ & Manufacturers use $3 \mathrm{D}$ printing at their own sites & $\begin{array}{l}\text { - } \quad \text { Reduced inventory levels } \\
\text { - } \quad \text { Reduced warehousing requirements } \\
\text { - } \text { Decentralized manufacturing }\end{array}$ \\
\hline $\begin{array}{l}\text { Customer-Managed } \\
\text { Inventory }\end{array}$ & $\begin{array}{l}\text { - Suppliers installing 3D printing at customer site } \\
\text { - Products and parts to be manufactured on demand }\end{array}$ & $\begin{array}{l}\text { - On-demand manufacturing } \\
\text { - } \quad \text { Reduced lead times of production } \\
\text { - } \text { Reduced supply chain costs } \\
\text { - } \quad \text { Customer empowerment }\end{array}$ \\
\hline 3D Printing Hub & $\begin{array}{l}\text { - 3D printing services are offered in hubs like Kinko's or } \\
\text { UPS stores } \\
\text { - Businesses or consumers can get their products printed } \\
\text { on submission of their design }\end{array}$ & $\begin{array}{l}\text { - On-demand custom fit and styling } \\
\text { - } \text { Customer empowerment } \\
\text { - } \text { Reduced delivery times } \\
\text { - } \text { Reduction in required inventory } \\
\text { - Increased on-time and in-full product delivery }\end{array}$ \\
\hline
\end{tabular}

\begin{tabular}{|l|l|l|l|}
\hline $\begin{array}{l}\text { Demand } \\
\text { Volumes }\end{array}$ & High & Moderate \\
\hline $\begin{array}{l}\text { Customization } \\
\text { Requirements }\end{array}$ & Low \\
\hline Responsiveness \\
Requirements
\end{tabular}

Figure 4. Most appropriate use of technology.

\section{Potential Impacts on Industries Supply Chain}

As AM technology evolves, it will lend itself to many amazing possibilities for companies to transform their supply chain operations. However, AM technology, like any other single technology, cannot solve all supply chain issues. It is crucial that this technology be applied appropriately to the right situation. Therefore, it is important to evaluate the potential impact of this technology on a company's supply chain strategy and planning before implementation.

\section{a) Effective Use of Technology}

According to a recent study, AM is best used for low-volume, customer specific, and moderate cost products requiring high customization and a short leadtime. Customer-specific items, items with high level of complexity are also good candidates. (Figure 4) [32].

Effective use of AM requires real-time visibility and flexible control across the supply chain including constant evaluation of new strategies, processes, and technologies. As AM is integrated to supplement traditional manufacturing, a supply chain collaboration and management solution can provide crucial infor- 
mation and control including early warning of delivery delays, route and sourcing optimization, and drop-ship management.

\section{b) Applications in Industries Supply Chain}

The breadth and impact of AM continues to expand as the technology gains acceptance and functionality, making it a feasible means of production in a variety of industries. While AM is primarily used as a way to make low-cost prototypes and mockups, the technology is multi-faceted and has many existing and possible uses. Table 6 summarizes applications and advantages of AM in major industries supply chain.

In the past few years, many companies have adopted AM and are beginning to rip the real benefits from the technology. Healthcare, automotive and aerospace industries are among the sectors with the greatest transformative potential. One of the first applications of AM was in the automotive industry. General Motors has been using AM to make prototypes for over 20 years in order to speed up time-to-market, help eliminate excess parts, and to reduce the cost involved in product development. The return on investment has been significant. Back in the early days the application of AM technology was limited to just vehicle mockups. Now, parts that would be difficult to quickly make any other waybumpers, grilles, spoilers, and mirrors can be accurately built using the technology [34]. Prototyping is not the only application of AM in the automotive industry. In 2011, Kor Ecologic unveiled the Urbee. The Urbee is the first car to have its exterior and interior completely printed. This helped eliminate excess parts that cause drag and add weight. While the car is currently a prototype for developing efficient vehicles, the company hopes to release the Urbee 2 for consumer use. The use of AM for automotive manufacturing could effectively change the way cars will look and function in the future [35]. The manufacturing of tools and parts is also another benefit applicable to the automotive industry. AM has the potential to simplify supply chains by reducing the number of assembly steps that a product must undergo. BMW is using the technology to print handheld tools that are used to attach bumpers and license plates [2]. The potential of AM to reduce labor inputs, the required tooling, and machining centers and inventory could change the future of auto industry.

AM technology has been pushed beyond the realm of prototyping and has become an effective means of advancing the way parts and tools are produced in the Aerospace industry. AM makes it possible to have objects printed in remote locations, as delivery of goods is no longer a restriction. This benefit of AM makes it possible for the use for technology in Space. NASA has been testing AM in zero gravity in hopes of establishing on-demand manufacturing for astronauts. This would allow component parts for maintenance and repair of the international space station to be manufactured in Space. This would decrease the need for shuttle to make trips to the international space station to deliver parts, thus greatly reducing the lead-time on replacement parts. A reduction in leadtime would imply a reduction in inventory and a reduction in costs. To quantify the cost reduction, transporting one pound of material into space amounts to 
Table 6. Potential impacts of AM technologies on industries supply chain.

\begin{tabular}{ll}
\hline \multicolumn{1}{c}{ Industry } \\
\hline Aerospace \\
- $\quad$ Design and rapid prototyping \\
- Component manufacturing \\
- Leaner manufacturing \\
- Improving process flexibility \\
- Decentralized, distributed \\
- production networks \\
\\
\\
Auss customization \\
- Simplified production processes \\
- Component manufacturing \\
- Mesign and rapid prototyping \\
- Leanufacturing at point of use \\
- Decentralized, distributed \\
\end{tabular}

Machine Tool Production

- Design \& rapid prototyping

- Leaner manufacturing

Healthcare and Medical

- Design and rapid prototyping

- Manufacturing at point of use

- Mass customization

Dentistry and Dental Technology

- Design and rapid prototyping

- Manufacturing at point of use

- Mass customization

\section{Architectural and Construction}

- Design and rapid prototyping

- Customization to customer requirement
- Light-weighting of aircraft

- Engine components for the Airbus

- Flight-certified hardware

- Airplane landing gear assemblies

- Manufacturing of satellite components

- Lockheed Martin is using the technology for the production of aerospace components

- In-space manufac. on the International Space Station

- Light-weighting of vehicles

- Cooling system for race cars

- GM has been using AM to make prototypes for over 20 years

- BMW is using the technology to print handheld tools

- Can be used in a back-up capacity

- Flexible enough to work on short notice and in unanticipated or urgent circumstances

- Lightweight grip system

- End-of-arm for smarter packaging

- Fabricating custom implants, such as hearing aids, and prosthetics

- Manufacturing human organs

- Reconstructing bones, body parts

- Hip joints, robotic hand, and skull implants

- Dental Coping

- Precisely tailored teeth and dental crowns

- Dental and orthodontic appliances

- Generating an exact scale model of the building

- Printing housing components
Benefits Gained

- Allow product lifecycle leverage

- Objects manufactured in remote locations, as delivery of goods is no longer a restriction

- A reduction in lead-time would imply a reduction in inventory and a reduction in costs

- Eliminate excess parts that cause drag and add weight

- Supply chain disintermediation

- Reduce labor inputs

- Reduce required tooling \& machining centers

- Hedge against disruptions

- Help eliminate excess parts

- Speed up time-to-market

- Reduce the cost involved in product development

- Simplifying supply chains by reducing the number of assembly steps that a product must undergo

- Supply chain disintermediation

- Reduce labor inputs

- Reduce required tooling \& machining centers

- Could change the way cars will look and function in the future

- Providing a contingency plan

- Quick production of exact and customized replacement parts on site

- Allow for designs that are more efficient and lighter

- Reductions in labor inputs, the required tooling and machining

- Reduction in required inventory

- Reduce surgery time and cost

- Reduce the risk of post-operative complications

- Reduce lead-time

- Reduce repair cost

- Improves process flexibility

- Great potential in the use of new materials

- Reduced lead-time

- Reduce repair cost

- Improving process flexibility

- Prosthetics could be fabricated in only a day, sometimes even in a few hours

- Producing scale models up to 60 percent lighter

- Reduce lead times of production by 50 to 80 percent

- The ability to review a model saves valuable time and money caused by rework

- Reduce construction time and manpower

- Increase customization

- Reduce construction cost

- Provide low cost housing to poverty-stricken areas

- Customer empowerment 


\section{Continued}

Retail/Apparel

- Design and rapid prototyping

- Manufacturing at point of use

- Mass customization

- decentralized, distributed production networks
- Shoes and clothing

- Fashion and consumer goods

- Consumer grade eyewear

- Eyeglass frames out of titanium

- Production of durable plastic and metal bicycle accessories
Food

- Manufacturing at point of use

- decentralized, distributed production networks
- Chocolate and candy

- Flat foods such as crackers, pasta, and pizza
- On-demand custom fit and styling

- Reduce supply chain costs

- Reduction in required inventory

- Deliver of small quantities of products in real time

- Create overall better products

- Products are getting to market quicker

- Management of demand uncertainty

- Customer empowerment

- Enables entry into new markets without huge capital cost

- Hedge against disruptions

- The ability to squeeze out food, layer by layer, into three-dimensional objects

- Reduce production cost

- Feasibility of printing food in space

- Reduction in required inventory

- Enables entry into new markets without huge capital cost

approximately $\$ 10,000$ [15]. Not only could this be used to make repairs on the international space station, but could also allow deep-spaced crewed missions, as parts could simply be manufactured on the shuttle. Having the ability to print on-demand decreases the amount of cargo space needed and the need for spare parts, thus circumventing the weight restrictions on spacecraft [22].

The applications of AM in manufacturing prosthetics, and even human organs are becoming an increasingly standard implementation of the technology. The Medical industry has found revolutionary ways to implement AM technology to reduce lead-time, reduce repair cost, and improves process flexibility. Fabricating custom implants, such as hearing aids and prosthetics was one of the first ways that AM transformed the medical industry [8]. Practitioners are now able to scan a patients using CAD software, produce a custom implant or prosthetic, and fit the individual with a custom component that is specified to the patient's unique needs. The custom made implants reduce surgery time and cost as well as reduce the risk of post-operative complications [2]. Lead-time is also greatly reduced. Before 3D printing, patients would have to have molds made, which would then be fabricated; a process that could take months. 3D printing allows prosthetics to be fabricated in only a day, sometimes even in a few hours [8].

3D printed shoes and clothing have already made their way into the market. 3D printed fashion and consumer goods are slowly making their way in the Retail industry. Retail is poised to gain some major advantages from innovations in AM. According to John Hauer, co-founder and CEO of 3DLT, AM's rapid prototyping abilities will create localized manufacturing, thus reducing supply chain costs and create overall better products. Huaure states "Products are getting to market quicker, arguably as better-designed products with more end-user feedback because they are able to play with a working model of the product" [20]. 
The time and money that goes into forecasting what consumers may want to buy in the future, and how much of the product should be made, can cost companies billions. "3D printers could allow retailers to create and deliver products in small quantities in real time, providing actionable insight into which products will actually drive demand. For example, if a 3D model is well received, it can then be mass-produced through traditional manufacturing channels to meet higher demand" [20].

\section{Summary and Conclusions}

McKinsey Global Institute named AM as one of the twelve disruptive technologies that will transform the business and the global economy by 2025. The business world is beginning to understand the potential of AM technologies for cost-effective, efficient, and environmentally friendly manufacturing. Almost every sector of the industry is riding on the AM opportunity bringing innovations to reality in industries like the automotive, aerospace, and medical. 3D printing started, mainly as a means to create prototypes. The recent technological advancements and applications of 3D printing suggest that the technology has potential to revolutionize many facets of everyday life. For manufacturers, AM most useful role may turn out to be more in enhancing supply chain capabilities or innovating across whole sections of those supply chains than in creating new products. The impact of AM on supply chains takes many forms, including simplified production processes, reduced material waste for leaner manufacturing, increased flexibility, reduced costs, faster reactions to demand, and the ability to decentralize production. Adopters can use the potential of AM to rethink sourcing of materials, product distribution, and the methods they use to deliver products to end users.

The rise of AM will greatly alter traditional (subtractive) manufacturing and supply chain. AM promises to be a powerful complement to traditional manufacturing and the end-to-end supply chain. Mass customization will become less expensive, consumers will become micro-manufacturers, and customer demands will be met more quickly. In addition, the supply chain will become more local, globally connected, and more efficient.

The implementation of the assembly line changed the way manufacturing works. AM is going to change the way manufacturing works in the future. AM has the potential to enable all of us to be manufacturers. There is a prediction that 3D printers are either going to be available at places like Kinko's, or at the homes of people like you and I.

\section{References}

[1] Wohlers Report (2013) Additive Manufacturing and 3D Printing: State of the Industry. Annual Worldwide Progress Report.

https://wohlersassociates.com/2013contents.htm

[2] Bogue, R. (2013) 3D Printing: The Dawn of a New Era in Manufacturing? Assembly Automation, 33, 307-311.

[3] Birtchnell, T., Urry, J., Cook, C. and Curry, A. (2013) Freight Miles: The Impact of 
3D Printing on Transport and Society. http://eprints.lancs.ac.uk/66198/1/Freight_Miles_Report.pdf

[4] Gravier, M. (2016) 3D Printing: Customers Taking Charge of the Supply Chain. Industry Week, April 12.

[5] Huang, S.H., Liu, P., Mokasdar, A. and Hou, L. (2013) Additive Manufacturing and Its Societal Impact: A Literature Review. The International Journal of Advanced Manufacturing Technology, 67, 1191-1203. https://doi.org/10.1007/s00170-012-4558-5

[6] Rayna, T. and Striukova, L. (2014) The Impact of 3D Printing Technologies on Business Model Innovation. In: Benghozi, P., Krob, D., Lonjon, A. and Panetto, H., Eds., Digital Enterprise Design \& Management, Springer, Berlin, 119-132. https://doi.org/10.1007/978-3-319-04313-5_11

[7] 3D Printing.com (2016) What Is 3D Printing. http://3dprinting.com/what-is-3d-printing/

[8] Berman, B. (2012) 3D Printing: The New Industrial Revolution. Business Horizons, 55, 155-162.

[9] Manners-Bell, J. and Lyon, K. (2012) The Implications of 3-D Printing for the Global Logistics Industry. http://johnmannersbell.com/wp-content/uploads/2013/11/The_impact_of_3D_Prin ting_on_Global_Supply_Chains.pdf

[10] Wohlers Report (2014) Additive Manufacturing and 3D Printing: State of the Industry. Annual Worldwide Progress Report.

https://wohlersassociates.com/2014contents.htm

[11] Van Lancker, P. (2015) 3D Printing: The Influence of Intellectual Property. CREAX, 12 August 2015.

https://www.creax.com/en/our-work/the-3d-printing-evolution-insights-on-the-infl uence-of-ip-on-technology-dev

[12] Bradshaw, S., Bowyer, A. and Haufe, P. (2010) The Intellectual Property Implications of Low-Cost 3D Printing. Scripted, 7, 5-31.

[13] Covert, A. (2014) 3-D Printing “Ink" Is Way Too Expensive. CNN Money, Cable News Network, 20 February 2014. http://money.cnn.com/2014/02/20/technology/innovation/3d-printer-filament/

[14] Janssen, G.R., Blankers, I.J., Moolenburgh, E.A. and Posthumus, A.L. (2014) The Impact of 3-D Printing on Supply Chain Management. TNO: Innovation for Life, April 2014.

[15] King, R. (2012) 3D Printing Coming to the Manufacturing Space and Outer Space. Bloomberg LP, Bloomberg.

[16] Royte, E. (2013) What Lies Ahead for 3-D Printing? Smithsonian Institute, Washington DC.

[17] Crandall, R. (2016) Where Will Additive Manufacturing Take Us? APICS, 26 June 2016.

[18] Earls, A. and Vinod, B. (2014) The Road Ahead for 3D Printers. http://www.pwc.com/us/en/technology-forecast/2014/3d-printing/features/future-3 d-printing.html

[19] Elms, D.K. and Low, P. (2013) Global Value Chains in a Changing World. World Trade Organization, Geneva.

[20] Honigman, B. (2014) How 3D Printing Is Reinventing Retail. Forbes Magazine, 3 June 2014 
[21] Lux Research (2013) Building the Future: Assessing 3D Printing's Opportunities and Challenges. Lux Research, Inc., Boston.

[22] NASA (2014) Space Tools on Demand: 3D Printing in Zero G. National Aeronautics and Space Administration, Washington DC. http://www.nasa.gov/sites/default/files/files/3D_Printing-v3.pdf

[23] Attaran, M. (2007) RFID: An Enabler of Supply Chain Management. Supply Chain Management. An International Journal, 12, 249-257. https://doi.org/10.1108/13598540710759763

[24] Attaran, M. (2011) Strategic Implications of RFID Implementations in the Retail Industry Supply Chain. International Journal of RF Technologies Research and Applications, 2, 155-171.

[25] Cohen, D., Sargeant, M. and Somers, K. (2014) 3-D Printing Takes Shape. McKinsey Quarterly, January 2014.

[26] Nyman, H.J. and Sarlin, P. (2014) From Bits to Atoms: 3D Printing in the Context of Supply Chain Strategies. 47 th Hawaii International Conference on System Science, Waikoloa, 6-9 January 2014, 4190-4199.

[27] Petrick, I.J. and Simpson, T.W. (2013) 3D Printing Disrupts Manufacturing How Economies of One Create New Rules of Competition. Research-Technology Management, 56, 12-16. https://doi.org/10.5437/08956308X5606193

[28] Tien, J. (2012) The Next Industrial Revolution: Integrated Services and Goods. Journal of Systems Science and Systems Engineering, 21, 257-296. https://doi.org/10.1007/s11518-012-5194-1

[29] Lipson, H. and Kurman, M. (2013) Fabricated: The New World of 3D Printing. John Wiley \& Sons, Hoboken.

[30] Sethi, J. (2014) 3D Printing and Its Implications for the Global Logistics Industry. http://electronicsmaker.com/3d-printing-and-its-implications-for-the-global-logisti cs-industry

[31] Alexander, C. (2015) Five Ways 3D Printing Is Transforming the Supply Chain. Supply \& Demand Chain Executive Blog, 8 April 2015.

[32] Kidd, A. and Sciacchitao, J. (2015) How 3D Printing Could Disrupt Your Supply Chain. 30 October 2015.

http://www.industryweek.com/supply-chain/how-3-d-printing-could-disrupt-yoursupply-chain

[33] Paris, H., et al. (2016) Comparative Environmental Impacts of Additive and Subtractive Manufacturing Technologies. CIRP Annals-Manufacturing Technology, 65, 29-32.

[34] Fish, E. (2011) Rapid Prototyping: How It's Done at GM. Automotive Design \& Production. http://www.adandp.media/articles/rapid-prototyping-how-its-done-at-gm

[35] Bargmann, J. (2013) Urbee 2, the 3D-Printed Car That Will Drive Across the Country. Popular Mechanics, Hearst Communications, 4 November 2013. 
Submit or recommend next manuscript to SCIRP and we will provide best service for you:

Accepting pre-submission inquiries through Email, Facebook, LinkedIn, Twitter, etc. A wide selection of journals (inclusive of 9 subjects, more than 200 journals)

Providing 24-hour high-quality service

User-friendly online submission system

Fair and swift peer-review system

Efficient typesetting and proofreading procedure

Display of the result of downloads and visits, as well as the number of cited articles Maximum dissemination of your research work

Submit your manuscript at: http://papersubmission.scirp.org/

Or contact jssm@scirp.org 